Chapter 9

\title{
Chromosome Abnormalities in \\ Domestic Animals as Causes of Disorders \\ of Sex Development or Impaired Fertility
}

\author{
Izabela Szczerbal and Marek Switonski \\ Additional information is available at the end of the chapter \\ http://dx.doi.org/10.5772/62053
}

\begin{abstract}
Cytogenetic evaluation is an important step in the diagnosis of infertile or sterile animals. Moreover, the analysis of sex chromosomes is crucial for a proper classification of disorders of sex development (DSD). For many years, chromosome studies mainly addressed the livestock species, while recently, increasing interest in such analysis in companion animals is observed. New molecular and cytogenetic tools and techniques have given opportunities for a precise identification of chromosome mutations. Among them, fluorescence in situ hybridization, besides chromosome banding, has become a gold standard. In this chapter, recent advances in the cytogenetic diagnosis of cattle, pigs, horses, dogs and cats are presented.
\end{abstract}

Keywords: Aneuploidy, translocation, intersexuality, sex reversal, freemartinism, trisomy, monosomy, centric fusion, inversion, chimerism, mosaicism

\section{Introduction}

Genetic background of disorders of sex development (DSD) and impaired fertility (IF) accompanied with normal sex development are important issues in animal breeding. The identification of the causative gene and chromosome mutations is especially important in these species, in which artificial insemination is a common reproduction technology. In such species, a routine cytogenetic evaluation of sires is conducted in numerous countries [1-5]. Chromosome studies are also recommended in the case of phenotypically normal males and females with IF, since it can be caused by balanced chromosomal translocations or inversions. Finally, the cytogenetic analysis is considered to be the first diagnostic step for DSD animals with 
ambiguous genitalia or abnormal sexual behaviour. The importance of chromosome analysis in the case of DSD was highlighted in livestock species [6, 7] and companion animals [8,9].

In this chapter, recent studies on chromosome abnormalities detected in domestic mammals, including livestock (cattle, pig and horse) and companion animals (dog and cat), are discussed. We focused on novel reports, which were not reviewed earlier [2, 7, 9].

\subsection{Historical overview of domestic animal cytogenetics}

Chromosome analyses of domestic mammals were started over 50 years ago. Their importance in animal breeding was pointed out by Ingemar Gustavsson, who identified a centric fusion (Robertsonian translocation) between chromosomes 1 and 29 in the Swedish Red and White cattle [10]. Five years later, an adverse influence on fertility of the carriers was documented [11]. Since this discovery, the development of veterinary cytogenetics of livestock species has been very rapid. It was found that $1 / 29$ centric fusion is widespread in cattle breeds, with an exception of Holstein-Friesian cattle [12]. In horses, $X$ monosomy appeared to be the most frequent chromosome abnormality [6], while in pigs reciprocal translocations were predominant [13].

The discovery of chromosome banding techniques was a crucial step for mammalian cytogenetics. The first banding technique was developed with the use of a fluorochrome, quinacrine mustard, on plant (broad bean, Vicia faba) chromosomes [14]. This type of banding was named Q-banding. Later, several other banding techniques were developed: G-banding, C-banding, R-banding, silver staining (Ag-I), etc. The use of these techniques in domestic animal cytogenetics was reviewed by Iannuzzi and Di Berardino [15].

Chromosome banding techniques facilitated the establishment of international standard karyotypes for domestic mammals. The standards are required for a precise diagnosis of chromosome aberrations. The first G-banded standards were published by Ford et al. [16] with the following species included in this report: the cattle, pig, horse, sheep, goat, cat and rabbit. In the following years, updated or novel standards were proposed for several species, including the pig [17], cattle, sheep, goat [18], horse [19], dog [20, 21] and cat [22].

Cytogenetic studies were revolutionized in the late 1980s by the use of a molecular technique named FISH (fluorescent in situ hybridization), based on the hybridization between labelled locus specific or whole chromosome painting probes with chromosomes on a microscopic slide [15]. This technique has become a gold standard in cytogenetic diagnosis, and it is commonly used for a precise and reliable detection of chromosomal structural abnormalities and aneuploidies. A wide range of molecular probes are commercially available for the human and the mouse, but not for domestic animal species. Therefore, a homemade preparation of the probes for these species is required. To obtain whole chromosome painting probes, very useful in cytogenetic diagnosis, microdissection of a given chromosome [23] or its flow sorting facilitate the amplification or molecular cloning of chromosome specific sequences [24, 25]. Also, locusspecific probes are useful in cytogenetic diagnosis, and such probes are derived from genome libraries, usually cloned in bacterial artificial chromosome (BAC) vectors (https:// bacpac.chori.org/). An example of both types of probes, applied for the detection of $\mathrm{X}$ and $\mathrm{Y}$ chromosomes, is presented in Fig. 1. 

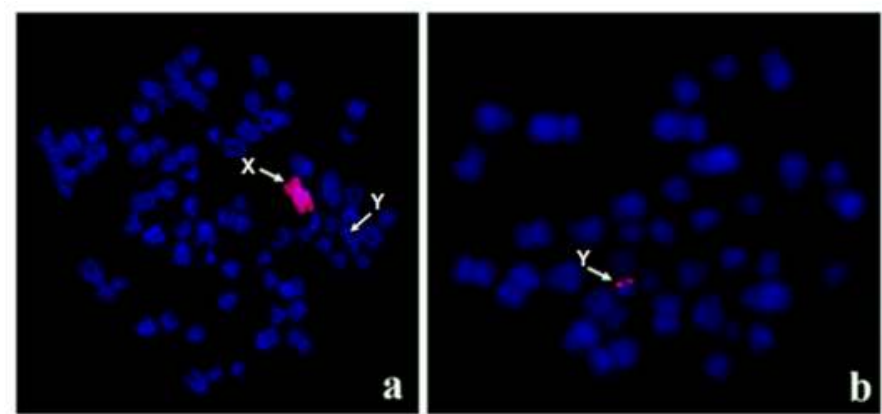

Figure 1. The use of FISH technique for the detection of sex chromosomes: (a) identification of the canine $\mathrm{X}$ chromosome (red), using a whole chromosome painting probe, (b) detection of the feline Y chromosome by the SRY-locus specific probe (red signal).

The latest achievements in developing molecular tools applied to cytogenetic diagnosis include SNP (single nucleotide polymorphism) microarrays and arrays for comparative genome hybridization $(\mathrm{aCGH})$. They may be used for a precise identification of break points leading to structural chromosome rearrangements. Recently, a new molecular karyotyping approach, based on the FISH technique, performed on a single microscopic slide, with a set of subtelomere-specific probes for both the $\mathrm{p}$ arm and the $\mathrm{q}$ arm of each chromosome has been developed [26]. It is foreseen that this tool will soon be commercialized for cattle and pig chromosomes.

\subsection{Chromosome abnormalities}

The diploid chromosome number $(2 n)$ is one of the characteristic features of a species (Table 1). In some species (e.g. the red fox, raccoon dog), a variable number of chromosomes, due to the presence of B chromosomes, is observed. Chromosomes are classified into four morphological categories, based on the arm ratio, which is a quotient of the long arm length divided by the short arm length.

\begin{tabular}{ccccc}
\hline \multirow{2}{*}{ Species } & 2n & \multicolumn{2}{c}{ Morphology of sex chromosomes* } \\
\cline { 3 - 4 } & & 60 & $\mathrm{~S}$ & $\mathrm{Y}$ \\
\hline Cattle & 54 & $\mathrm{~A}$ & $\mathrm{M}$ \\
\hline Sheep & 60 & $\mathrm{~A}$ & $\mathrm{M}$ \\
\hline Goat & 38 & $\mathrm{M}$ & $\mathrm{M}$ \\
\hline Pig & 64 & $\mathrm{SM}$ & $\mathrm{A}$ \\
\hline Horse & 78 & $\mathrm{SM}$ & $\mathrm{M}$ \\
\hline Dog & 38 & $\mathrm{M}$ & $\mathrm{M}$ \\
\hline Cat &
\end{tabular}

* $\mathrm{M}$ - metacentric, $\mathrm{SM}$ - submetacentric, A - acrocentric

Table 1. Chromosome number and sex chromosome morphology in selected domestic mammals 
The effect of chromosome abnormalities, classified into three main categories (Fig. 2), is not uniform. Euploidies, autosomal aneuploidies and large unbalanced structural rearrangements usually cause early embryonic death. An exception is found in sex chromosome aneuploidies, which usually are not lethal but are responsible for disorders of sex development. Balanced chromosome rearrangements cause impaired fertility due to the mortality of embryos with an unbalanced chromosome complement.

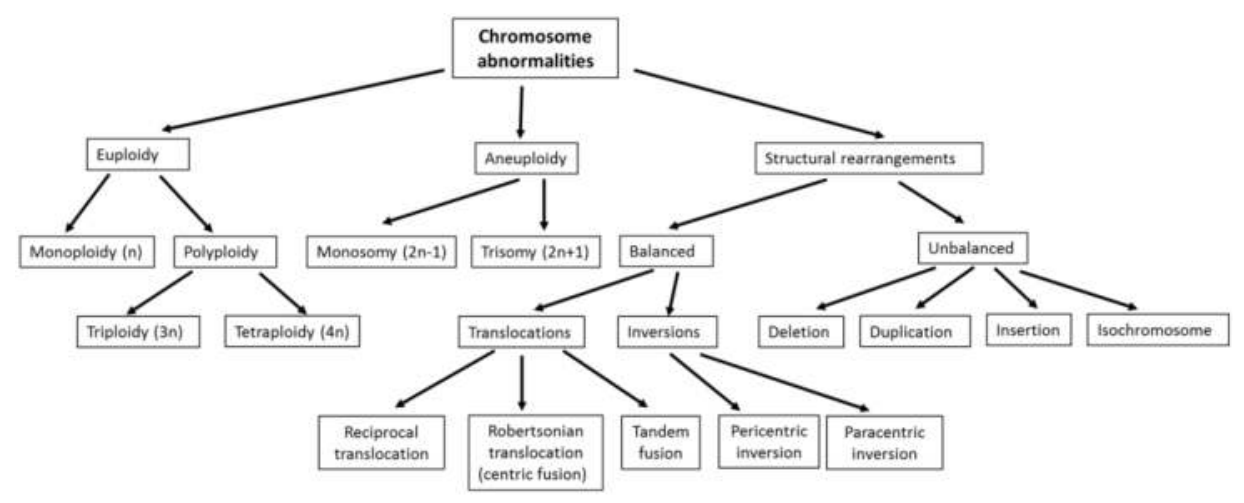

Figure 2. Classification of chromosome abnormalities.

An analysis of the sex chromosome complement is required to diagnose disorders of sex development. The use of conventional Giemsa-stained chromosomes facilitates the identification of $X$ and $Y$ chromosomes in the cattle and dog (Fig. 3), while in others, it is not an easy task. In the cat and horse, the morphology of both sex chromosomes is similar to some autosomes, and their identification requires the application of the banding or FISH techniques. In the pig, only the $\mathrm{Y}$ chromosome is easily recognized.
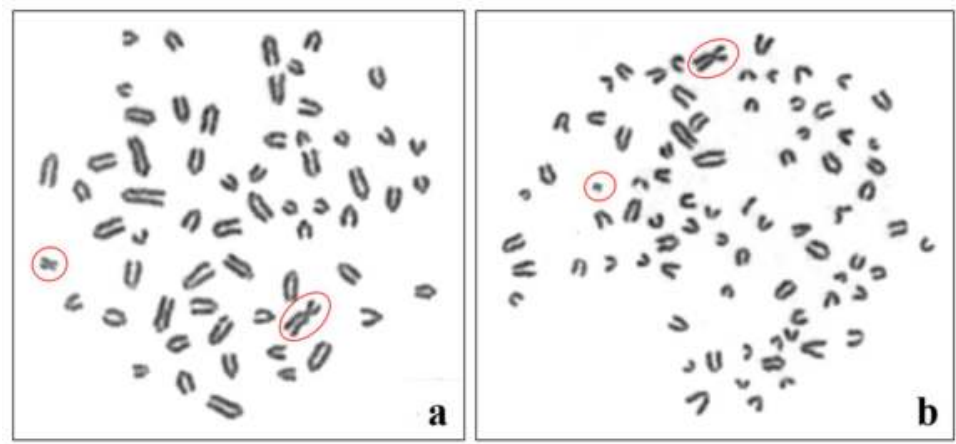

Figure 3. Giemsa-stained metaphase spreads: (a) bull, $2 n=60, X Y$, (b) male dog, $2 n=78, X Y$. Bi-armed sex chromosomes are indicated: $X$ (large) and Y (small). 


\subsection{Classification of disorders of sex development}

The sex determination of mammals is a very complex process, in which sex chromosomes and dozens of genes are involved [27]. A majority of these genes are localized on autosomes, and only a few of them reside on the sex chromosomes, including SRY (sex determining region Y), triggering male differentiation of the gonads and located on the $\mathrm{Y}$ chromosome, and $A R$ (androgen receptor), involved in the development of Wolffian ducts and external male genitalia, having its locus on the $\mathrm{X}$ chromosome. Interestingly, crucial genes for ovary differentiation, i.e. RSPO1 (R-spondin 1), CTTNB1 (catenin beta 1), WNT-4 (wingless-type mouse mammary tumor virus integration site family, member 4) and FOXL2 (forkhead box L2), are localized on autosomes.

Due to the crucial role of sex chromosomes (especially the $Y$ chromosome in male determination), mammalian DSDs are classified into three main categories, based on sex chromosome complement: (1) sex chromosome DSD, (2) XX DSD and (3) XY DSD. This classification was originally developed for human DSDs [28], later adopted for companion animals (the dog and cat) $[8,9]$, and it may also be applied to mammalian livestock.

The sex chromosome DSD comprises sex chromosome aneuploidies, structural rearrangements involving sex chromosomes and lymphocyte chimerism (XX/XY) observed in freemartins. In XX DSD animals, a major abnormality, diagnosed in several species (goat, pig, horse and $\operatorname{dog}$ ), is manifested by the presence of testicles or ovotestes, as well as the uterus with oviducts and duct deferens in spite of the lack of the SRY gene. The XY DSD includes monogenic abnormalities, e.g. androgen insensitivity syndrome (AIS) and persistent Mullerian duct syndrome (PMDS), as well as syndromes in which the background is elusive or complex (e.g. cryptorchidism and hypospadias).

\subsection{Meiosis in carriers of chromosome abnormalities}

Meiosis is a crucial step of gametogenesis, and its alteration may cause impaired fertility. Unbalanced chromosome segregation at meiotic anaphase I or anaphase II may occur in animals with a normal chromosome set. As a consequence, among normal, haploid gametes a low proportion of unbalanced gametes can be present. The fertilization of such gametes leads to the development of embryos with an abnormal chromosome number. A majority of embryos with an autosomal aneuploidy die during early prenatal development, and decreased fertility of the carrier is noticed. In contrast, sex chromosome aneuploidies, especially trisomies, are not lethal.

The risk of unbalanced segregation is increased in gametogenesis of carriers of structural chromosome aberrations. It is well known that in gametogenesis of such carriers, chromosome pairing at meiotic prophase I is altered and, as a consequence, an unbalanced chromosome segregation at anaphase I may occur. Since the carriers produce normal and unbalanced gametes, the chromosome abnormality is inherited by $50 \%$ of the offspring.

Chromosome pairing at the pachytene substage of prophase I is usually studied by visualization of synaptonemal complexes under light or electron microscopies [29]. A postnatal study of chromosome pairing is possible only in males, because female meiosis starts during foetal 
life. Recently, the use of immunofluorescent visualization of proteins building synaptonemal complexes (e.g. SCP1 - synaptonemal protein 1) or engaged in crossing over (e.g. MLH1) has become more common [30].

Meiotic chromosome segregation at anaphase I can be studied postnatally in females and males. To study the segregation in females, in vitro maturation of oocytes is usually applied to obtain chromosome spreads at metaphase II. The spreads can be conventionally stained with Giemsa dye or analysed with the use of in situ hybridization approach, e.g. comparative genomic hybridization (CGH) [31]. The segregation analysis in spermatogenesis is usually carried out on sperms hybridized with fluorescently labelled locus-specific probes [32].

\subsection{Mosaicism and chimerism}

Chromosome studies of an individual sometimes reveal the presence of two or more cell lines with different chromosome complements. Such a situation may be classified as chromosome mosaicism or chimerism. Mosaicism is a condition when cell lines are derived from one embryo and are produced by unbalanced sister chromosome segregation during the mitotic anaphase. The incidence of mosaicism is frequent in animals with sex chromosome aneuploidies, e.g. a majority of infertile mares with $\mathrm{X}$ monosomy are mosaics with two cell lines - normal $(64, \mathrm{XX})$ and monosomic $(63, X)$. The presence of cell lines derived from different embryos is called chimerism. A classic example is the lymphocyte chimerism (with XX and XY chromosome sets) in heterosexual twins or multiplets, which developed placental anastomoses.

Mosaicism and chimerism are commonly diagnosed in animals with disorders of sex development. Thus, the identification of two or more cell lines is an important diagnostic issue. Since the incidence of the second cell line can be low, its detection requires analyses of a large number of metaphase spreads. For example, to exclude the presence of another cell line at the level of, e.g. 3\% (with $95 \%$ confidence), 100 metaphase spreads should be analysed [33]. Moreover, the molecular analysis of genetic markers, e.g. microsatellites, is required to distinguish between lymphocyte and whole body chimerism [34].

\section{Sex chromosome DSD}

The first step of DSD diagnosis, following clinical investigation, should be cytogenetic analysis focused on the identification of sex chromosomes. This analysis facilitates the identification of DSDs caused by chromosome abnormalities: $X X / X Y$ chimerism present in freemartins or sex

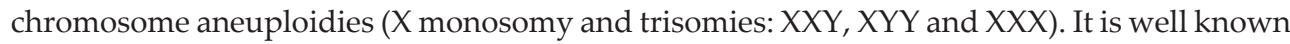
that sex chromosome DSDs usually cause infertility or sterility [7], but it should be pointed out that some of them are associated with an increased risk of gonad malignancy [35].

\section{1. $X X / X Y$ lymphocyte chimerism}

Freemartinism, observed in females originating from heterosexual pregnancies, is the most common and extensively studied DSD in cattle and other ruminants [36,37]. The frequency of 
freemartinism depends on the incidence of twin (multiple) pregnancies associated with the development of placental anastomoses between embryos. The anastomoses in bovine twin pregnancies are developed very often (over $90 \%$ ). In contrast, the incidence of twinning is rather low (2-5\%); however, in recent years, an increasing trend is observed in dairy cattle breeds [38]. The cytogenetic detection of the XY cell line, originating from a male co-twin, can be difficult in a female co-twin, if it occurs with a low frequency. It is not exceptional for the frequency of the $X Y$ cell line to be below $5 \%$. Therefore, the use of molecular detection of genes localized on the Y chromosome (SRY, ZFY or AMELY), along with cytogenetic analysis, is recommended [39]. Chimerism was also observed in heifers originating from a single birth, the so-called singletons [38]. The authors analysed cytogenetically and molecularly 12 heifer singletons with underdeveloped internal genitalia and found 7 with lymphocyte $\mathrm{XX} / \mathrm{XY}$ chimerism among them. It indicated that during the foetal life, a male co-twin embryo died after the development of placental anastomoses. This report showed that the incidence of bovine freemartins is underestimated. In the bovine male co-twin, chimerism is detected, but these males are normally developed with no sign of DSD. Among other ruminants, freemartinism was quite extensively studied in sheep, and the incidence of this DSD, diagnosed by a chromosome study, was around 5\% XX/XY [40,41]. Studies in goats also indicate that the frequency of freemartins is similar to that in sheep [42].

The lymphocyte $X X / X Y$ chimerism was also reported in non-ruminant females. This condition was identified in horses [43, 44], pigs [45] and dogs [34]. A normal phenotype was reported in chimeric mares, but they were not clinically examined, thus the conclusion concerning their sex development and fertility is still a matter of controversy. In contrast, in chimeric female dogs, the sex development is usually altered [9], and in some cases, ambiguous external genitalia were observed [34, 46].

Sex development and fertility of XX/XY chimeric males are usually unaffected [7]. Such males are diagnosed during the routine cytogenetic examination of sires, mainly bulls and boars, used in artificial insemination (AI). Recently, an extensive study on fertility of seven chimeric AI boars was carried out by Barsac et al. [45]. The authors concluded that this condition has a non-significant effect on their reproductive performance. An unusual case of lymphocyte chimerism was reported by Demyda-Peyras et al. [47], who identified 64,XY (approx. 96\%) and $63, \mathrm{X}$ (approx. $4 \%$ ) cell lines in a phenotypically normal colt.

\subsection{Sex chromosome aneuploidies}

The most deleterious effects on sex development, leading to sterility, are caused by X monosomy and XXY trisomy (Table 2). The incidence of sex chromosome aneuploidies is not uniform across species. The $\mathrm{X}$ monosomy is most common in mares, rather rare in dogs and cats, and very rare in cattle and pigs. In turn, the $X X Y$ trisomy is diagnosed rather rarely, with an exception of tortoiseshell male cats. Two other sex chromosome aneuploidies (XXX and XYY) were reported incidentally. These rough estimations should be taken with caution, because mainly males are cytogenetically analysed, and their numbers are not comparable across species - very large in cattle, large in pigs and rather small in dogs and cats. In contrast, in horses, the number of studied mares is much larger than that of stallions. 


\begin{tabular}{llll}
\hline Mutation & The most common clinical features & $\begin{array}{l}\text { Effects on } \\
\text { fertility }\end{array}$ & $\begin{array}{l}\text { Decreasing incidence in } \\
\text { different species }\end{array}$ \\
\hline X monosomy & $\begin{array}{l}\text { Usually normal external genitalia; abnormal } \\
\text { oestrus or no clinical signs of oestrus; small or } \\
\text { hypoplastic ovaries }\end{array}$ & $\begin{array}{l}\text { Sterility } \\
\text { XXX trisomy }\end{array}$ & $\begin{array}{l}\text { Horse > cat and dog > cattle and } \\
\text { pig }\end{array}$ \\
& clinical signs, sometimes irregular oestrus & Infertility & Dog, horse \\
\hline XXY trisomy & $\begin{array}{l}\text { Small and hypoplastic testes; abnormal } \\
\text { spermatogenesis (oligospermia or }\end{array}$ & Sterility & Cat and cattle > dog and horse > \\
& azoospermia) & pig \\
\hline XYY trisomy & Usually normal phenotype; small testes & Infertility & Cattle \\
\hline
\end{tabular}

Table 2. Aneuploidies and their impact on fertility

The incidence of $X$ monosomy was evaluated in a screening study of young and phenotypically normal horses [48]. The authors analysed karyotypes of 500 horses, including 262 mares and 228 stallions. Among them, eight mares (3.1\%) with X monosomy were identified, while all males had a normal karyotype. This study strongly confirmed that $\mathrm{X}$ monosomy is the most important cause of equine DSD. In cattle, this aneuploidy is very rare, and a second case of this abnormality was recently described in a 3-year-old Longhorn heifer with normal external genitalia, an underdeveloped uterus and gonads unidentifiable by rectal ultrasonography [49]. Several cases of $X$ monosomy were diagnosed in dogs and cats [9], and the most recent report concerns an unusual case of feline $\mathrm{X}$ monosomy - Fig. 4 [50]. This animal presented a virilized phenotype, manifested by a rudimentary penis and scrotum-like structure. Interestingly, the histological examination of the gonad revealed the presence of corpora lutea and primordial follicles.

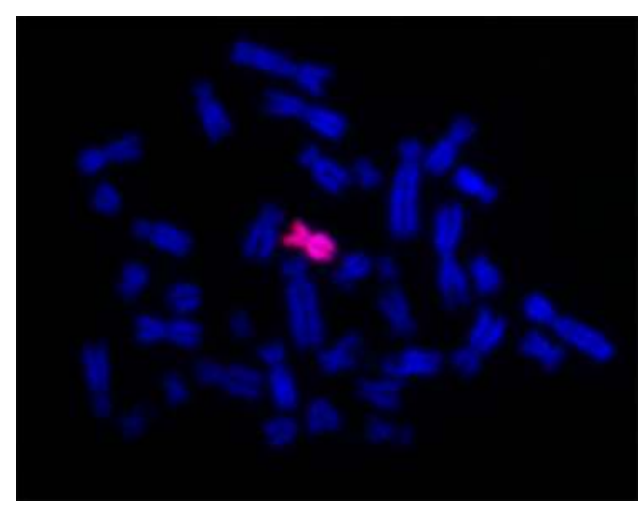

Figure 4. Metaphase spread with $X$ monosomy $(37, X)$ in a cat with a virilised phenotype. Application of whole $X$ chromosome painting probe facilitated identification of a single $X$ chromosome. For details, see Szczerbal et al. [50]. 
The largest number of XXY trisomy cases was reported in tortoiseshell male cats, and recently such a case was described [51]. In cattle, more than 20 cases of this abnormality were diagnosed in infertile bulls $[2,3]$. However, it was rarely diagnosed in pigs, horses and dogs. A recent report concerned a mosaic 39, XXY/38, $X Y$ azoospermic young boar, recruited for artificial insemination [52]. The authors analysed the chromosome constitution in lymphocytes and fibroblasts culture derived from the gonads. In both tissues, a prevalence of the trisomic cell line (approx. 95\%) was observed. It is known that XXY trisomy in men is associated with an elevated risk of malignancy. Such a case was also reported in a XXY trisomic dog, suffering from testicular cancer [53].

Two other common sex chromosome aneuploidies ( $X X X$ and $X Y Y$ ) were rarely reported in domestic mammals. Several such cases were described in horses, cattle and dogs. The carriers usually are infertile, e.g. an XXX mare [54] and an XXX female dog [55].

\section{Decreased fertility in carriers of balanced chromosome aberrations}

Balanced structural rearrangements (centric fusions, tandem fusions, reciprocal translocations and inversions) are inheritable mutations, which affect the fertility of carriers, without a visible alteration of sex development. The most pronounced decrease of fertility is associated with reciprocal translocations, including sterility of males carrying the X-autosome or Y-autosome rearrangements. In contrast, the fertility of carriers of other balanced aberrations (centric fusions, tandem fusions and inversions) is only slightly decreased.

\subsection{Centric fusions (Robertsonian translocations)}

Centric fusions are the most extensively studied chromosome aberrations in domestic mammals due to the discovery of a wide distribution of the $1 / 29$ centric fusion in cattle. It was recently shown with the use of advanced molecular techniques that the $1 / 29$ mutation is not a simple centric fusion, but it is a complex rearrangement including deletion, inversion and centric fusion [56].

The $1 / 29$ Robertsonian translocation was identified in numerous cattle breeds, but it seems to be absent in Holstein-Friesian cattle, the most important dairy breed. In some beef breeds, its incidence exceeds 10\% [2], while in some local breeds, e.g. in Portugal, the frequency of the carriers is above $50 \%$ [57]. Also, other types of centric fusions, involving other autosomes, were described in cattle [58]. In sheep, goats, pigs and dogs, centric fusions were rather rarely identified, while in horses and cats, there are no such reports.

The fertility of centric fusion carriers is slightly altered due to the formation of a trivalent [59] and its abnormal segregation at meiotic anaphase I [60], leading to the formation of aneuploid embryos, which die at early embryonic stages of development. In the case of bull carriers, the non-return ratio (NRR) is decreased by approx. $5 \%$, but the aberration is inherited by $50 \%$ of the offspring. Interestingly, in pig carriers of the 13/17 Robertsonian translocation, the rate of unbalanced gametes due to the abnormal segregation of the trivalent was low in sperms (approx. 3\%) and much higher in secondary oocytes (approx. 19\%) [61]. 


\subsection{Reciprocal translocations}

Reciprocal translocations are the most common chromosome rearrangements in pigs. It was estimated that an overall frequency of these rearrangements among 7,700 young boars cytogenetically evaluated in France was $0.47 \%$ [1]. Altogether, over 130 different translocations were identified in this species by 2012 [62], and novel cases were published in recent years (Table 3, Fig. 5).

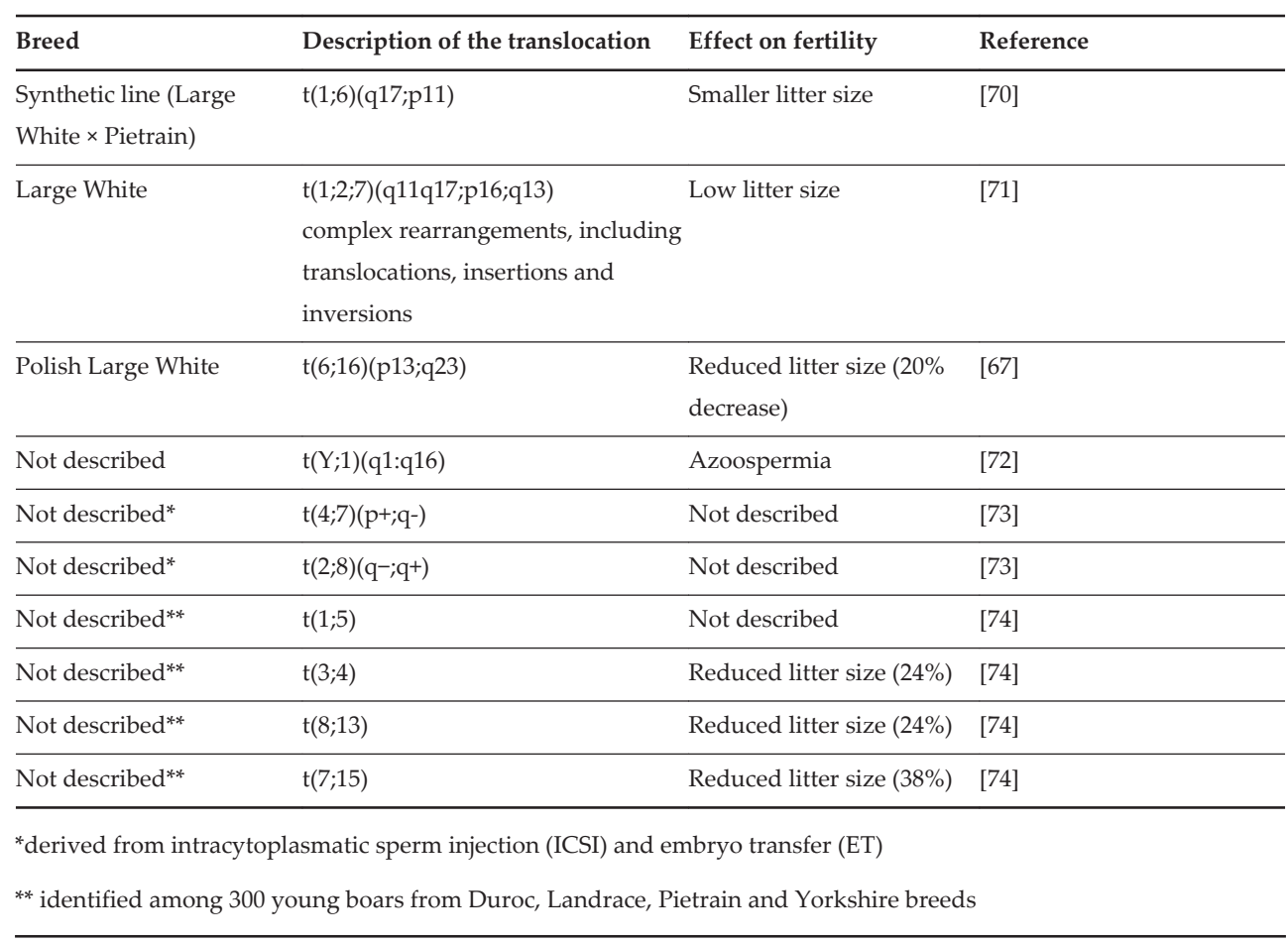

Table 3. Reciprocal translocations in pigs reported in 2011-2015 (not included in the review by Raudsepp and Chowdhary [62]).

The incidence of reciprocal translocations in cattle, the most extensively cytogenetically studied species, is much lower. In the literature, there are reports on 21 different cases of reciprocal translocations, including two cases of the $\mathrm{X}$-autosome and another two cases of $\mathrm{Y}$ autosome translocations [63]. A low incidence of the translocation carriers seems to be a result of the limited resolution of the commonly used Giemsa staining This approach is sufficient to detect aneuploidies and centric fusions but does not facilitate the detection of a majority of reciprocal translocations. Interesting statistical and simulation estimations were performed by de Lorenzi et al. [64], who suggested that approx. only $16 \%$ of reciprocal translocations can be detected using Giemsa staining. Taking into consideration a real number of the identified 


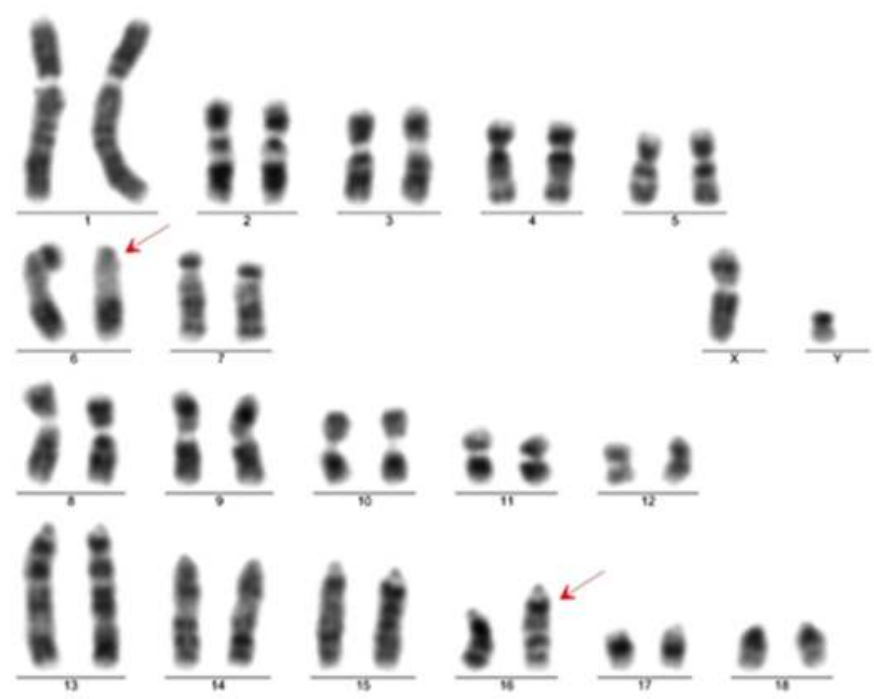

Figure 5. G-banded karyotype of a boar carrier of reciprocal translocation - t(6;16)(p13;q23). For details, see Kociucka et al. [67].

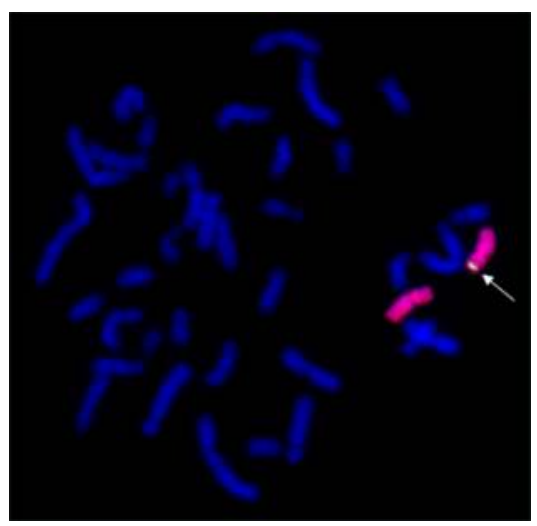

Figure 6. Metaphase spread with a translocation between $X$ and $Y$ chromosomes $-t(X ; Y)(p 22 ; p 12)$, in a cat with disorder of sex development. FISH technique facilitated the localization of SRY gene (arrow) on X chromosome. For details, see Szczerbal et al. [66].

translocations and this estimation, they suggested that the frequency of this chromosome is $<0.14 \%$. It would be three-fold less than in pigs.

In other domestic mammals, reciprocal translocations were rarely identified. In mares suffering from repeated early embryonic loss, three translocations, including two reciprocal, were identified between autosomes: $\mathrm{t}(1 ; 21), \mathrm{t}(16 ; 22)$ and $\mathrm{t}(4 ; 13)$ [65]. An interesting case was 
reported by Szczerbal et al. [66], who for the first time in domestic mammals diagnosed a translocation between the $X$ and $Y$ chromosomes, $t(X ; Y)(p 22 ; p 12)$, in a female cat $(38, X X)$ with a disorder of sex development, manifested by the presence of a rudimentary penis (Fig. 6).

Similarly to centric fusions, decreased fertility is caused by the abnormal segregation of a tetravalent during anaphase I. However, the proportion of chromosomally unbalanced gametes is much higher in carriers of reciprocal translocations and varies between 20 and $50 \%$ [67]. As a consequence, a large proportion of the embryos die at an early embryonic stage, and thus the decrease of fertility is much more pronounced. In the case of reciprocal translocations involving sex chromosomes, the carriers are usually infertile, with an exception of the female carriers, which are infertile (Table 4).

\begin{tabular}{|c|c|c|c|}
\hline Type of mutation & Most common features & $\begin{array}{l}\text { Reduction of } \\
\text { fertility }\end{array}$ & $\begin{array}{l}\text { Incidence, according to the number } \\
\text { of reported cases }\end{array}$ \\
\hline Robertsonian translocation & $\begin{array}{l}\text { Normal phenotype; normal } \\
\text { libido; normal semen picture; } \\
\text { lower non-return rate (cattle) }\end{array}$ & $5 \%$ & $\begin{array}{l}\text { Cattle - frequently in local breeds } \\
\text { and some beef breeds } \\
\text { Pig, dog - rare }\end{array}$ \\
\hline $\begin{array}{l}\text { Reciprocal translocation } \\
\text { autosome/autosome }\end{array}$ & $\begin{array}{l}\text { Normal phenotype; decreased } \\
\text { litter size (pig), decreased } \\
\text { non-return rate (cattle) }\end{array}$ & $20-50 \%$ & $\begin{array}{l}\text { Pig - frequently } \\
\text { Cattle, horse - rare }\end{array}$ \\
\hline \multirow[t]{2}{*}{$\begin{array}{l}\text { Reciprocal translocation } \\
\text { X/autosome }\end{array}$} & $\begin{array}{l}\text { Females: normal phenotype; } \\
\text { decreased litter size (pig) }\end{array}$ & $20-50 \%$ & Pig, cattle, dog, horse - rare \\
\hline & $\begin{array}{l}\text { Males: abnormal } \\
\text { spermatogenesis } \\
\text { (oligospermia or azoospermia) }\end{array}$ & Sterility & \\
\hline $\begin{array}{l}\text { Reciprocal translocation } \mathrm{Y} / \\
\text { autosome }\end{array}$ & $\begin{array}{l}\text { Males: abnormal } \\
\text { spermatogenesis } \\
\text { (oligospermia or azoospermia) }\end{array}$ & Sterility & Pig, cattle - rare \\
\hline $\begin{array}{l}\text { Translocation } \\
\mathrm{X} / \mathrm{Y}\end{array}$ & $\begin{array}{l}\text { Disorder of sex development, } \\
\text { including abnormal external } \\
\text { genitalia }\end{array}$ & Sterility & $\begin{array}{l}\text { Only one case in a cat has been } \\
\text { diagnosed to date }\end{array}$ \\
\hline
\end{tabular}

Table 4. An overview of chromosome translocations in domestic mammals: phenotype, fertility and incidence

\subsection{Other balanced chromosome rearrangements}

Chromosome inversions were diagnosed in cattle and pigs, but their impact on fertility of the carriers is poorly recognized. Among different cases of inversions, one is of special interest. It was a pericentric inversion of the pig chromosome $4-\operatorname{inv}(4)(\mathrm{p} 1.4 ; \mathrm{q} 2.3)$, which was diagnosed in several AI boars in France. Analyses of sperms and oocytes of the male and female carriers showed the incidence of unbalanced gametes to be approx. $4 \%$ [68].

Tandem fusions were very rarely diagnosed in domestic mammals. In recent years, such a rearrangement was diagnosed in a young boar with a normal phenotype and semen character- 
istics [69]. In the tandem fusion, two acrocentrics were involved: t(14;17)(q29;q10). The carrier was not accepted for use in artificial insemination.

\section{Conclusions}

The long history of cytogenetic evaluation of domestic mammals, mainly applied to males used in artificial insemination, showed that heritable, balanced chromosome abnormalities do not cause visible phenotypic effects but are responsible for impaired fertility. Therefore, young males considered as candidates for use in artificial insemination stations are commonly cytogenetically evaluated. It is important to point out that the first step for the classification of sex development disorders is cytogenetic analysis. Eventually, the use of chromosome studies plays a crucial role in searching for causes of infertility of phenotypically normal animals, as well as individuals with an abnormal sex development.

\section{Acknowledgements}

This study was financed by the National Science Centre in Poland - grant 2012/05/B/NZ9/00907

\section{Author details}

Izabela Szczerbal and Marek Switonski*

*Address all correspondence to: switonsk@up.poznan.pl

Department of Genetics and Animal Breeding, Poznan University of Life Sciences, Poznan, Poland

\section{References}

[1] Ducos A, Berland HM, Bonnet N, Calgaro A, Billoux S, Mary N, Garnier-Bonnet A, Darré R, Pinton A. (2007). Chromosomal control of pig populations in France: 2002-2006 survey. Genet Sel Evol. 39: 583-597.

[2] Ducos A, Revay T, Kovacs A, Hidas A, Pinton A, Bonnet-Garnier A, Molteni L, Slota E, Switonski M, Arruga MV, van Haeringen WA, Nicolae I, Chaves R, Guedes-Pinto H, Andersson M, Iannuzzi L. (2008). Cytogenetic screening of livestock populations in Europe: an overview. Cytogenet Genome Res. 120: 26-41. 
[3] Citek J, Rubes J, Hajkova J. (2009). Robertsonian translocations, chimerism, and aneuploidy in cattle. J Dairy Sci. 92: 3481-3483.

[4] Krumrych W (2009). Overview of the cytogenetic evaluation of young bulls bred in the north-western part of Poland in 1999-2008. Bull Vet Inst Pulawy. 53: 669-672.

[5] Quach TA, Villagómez DA, Coppola G, Pinton A, Hart EJ, Reyes ER, Basrur PK, King WA. (2009). A cytogenetic study of breeding boars in Canada. Cytogenet Genome Res. 126: 271-280.

[6] Lear TL, McGee RB. (2012). Disorders of sexual development in the domestic horse, Equus caballus. Sex Dev. 6: 61-71.

[7] Favetta LA, Villagómez DA, Iannuzzi L, Di Meo G, Webb A, Crain S, King WA. (2012). Disorders of sexual development and abnormal early development in domestic food-producing mammals: the role of chromosome abnormalities, environment and stress factors. Sex Dev. 6: 18-32.

[8] Poth T, Breuer W, Walter B, Hecht W, Hermanns W. (2010). Disorders of sex development in the dog-adoption of a new nomenclature and reclassification of reported cases. Anim Reprod Sci. 121: 197-207.

[9] Meyers-Wallen VN. (2012). Gonadal and sex differentiation abnormalities of dogs and cats. Sex Dev. 6: 46-60.

[10] Gustavsson I, Rockoborn G. (1964). Chromosome abnormality in three cases of lymphatic leukaemia in cattle. Nature 203: 990.

[11] Gustavsson I. (1969). Cytogenetics, distribution and phenotypic effects of a translocation in Swedish cattle. Hereditas. 63: 68-169.

[12] Switonski M. (2014). 50 years of studies on bovine 1/29 Robertsonian translocation from Giemsa staining to genomic analysis. Chromosome Res. 22: 395.

[13] Long SE. (1991). Reciprocal translocations in the pig (Sus scrofa): a review. Vet Rec. 128: $275-278$.

[14] Caspersson T, Zech L, Modest EJ, Foley GE, Wagh U, Simonsson E. (1969). Chemical differentiation with fluorescent alkylating agents in Vicia faba metaphase chromosomes. Exp Cell Res. 58: 128-140.

[15] Iannuzzi L, Di Berardino D. (2008). Tools of the trade: diagnostics and research in domestic animal cytogenetics. J Appl Genet. 49: 357-366.

[16] Ford CE, Pollock DL, Gustavsson I. (1980). Proceedings of the First International Conference for the standardisation of banded karyotypes of domestic animals. University of Reading Reading, England. 2nd-6th August 1976. Hereditas. 92: 145-162.

[17] Gustavsson I. (1988). Standard karyotype of the domestic pig. Committee for the Standardized Karyotype of the Domestic Pig. Hereditas. 109: 151-157. 
[18] Cribiu EP, Di Berardino D, Di Meo GP, Eggen A, Gallagher DS, Gustavsson I, Hayes H, Iannuzzi L, Popescu CP, Rubes J, Schmutz S, Stranzinger G, Vaiman A, Womack J. (2001). International System for Chromosome Nomenclature of Domestic Bovids (ISCNDB 2000). Cytogenet Cell Genet. 92: 283-299.

[19] Bowling AT, Breen M, Chowdhary BP, Hirota K, Lear T, Millon LV, Ponce de Leon FA, Raudsepp T, Stranzinger G. (1997). International system for cytogenetic nomenclature of the domestic horse. Report of the Third International Committee for the Standardization of the domestic horse karyotype, Davis, CA, USA, 1996. Chromosome Res. 5: 433-443.

[20] Switonski M, Reimann N, Bosma AA, Long S, Bartnitzke S, Pieńkowska A, MorenoMilan MM, Fischer P. (1996). Report on the progress of standardization of the Gbanded canine (Canis familiaris) karyotype. Committee for the Standardized Karyotype of the Dog (Canis familiaris). Chromosome Res. 4: 306-309.

[21] Breen M, Bullerdiek J, Langford CF. (1999). The DAPI banded karyotype of the domestic dog (Canis familiaris) generated using chromosome-specific paint probes. Chromosome Res. 7: 401-406.

[22] Cho KW, Youn HY, Watari T, Tsujimoto H, Hasegawa A, Satoh H. (1997). A proposed nomenclature of the domestic cat karyotype. Cytogenet Cell Genet. 79: 71-78.

[23] Bugno M, Słota E, Pieńkowska-Schelling A, Schelling C. (2009). Identification of chromosome abnormalities in the horse using a panel of chromosome-specific painting probes generated by microdissection. Acta Vet Hung. 57: 369-381.

[24] Graphodatsky A, Ferguson-Smith MA, Stanyon R. (2012). A short introduction to cytogenetic studies in mammals with reference to the present volume. Cytogenet Genome Res. 137: 83-96.

[25] Rubes J, Musilova P, Mastromonaco GF. (2008). Cytogenetics of wild and captive bred non-domestic animals. Cytogenet Genome Res. 120: 61-68.

[26] O'Connor RE, Fonseka G, D.K. Griffin DK (2014). Identification of chromosomal translocations in pigs using FISH with subtelomeric probes and the development of a novel screening tool for their application. Chromosome Res. 22: 396-397.

[27] Eggers S, Sinclair A. (2012). Mammalian sex determination-insights from humans and mice. Chromosome Res. 20: 215-238.

[28] Pasterski V, Prentice P, Hughes IA (2010). Impact of the consensus statement and the new DSD classification system. Best Practice Res Clin Endocrinol Metab. 24: 187-195.

[29] Switonski M, Stranzinger G. (1998). Studies of synaptonemal complexes in farm mammals - a review. J Hered. 89: 473-480.

[30] Mary N, Barasc H, Ferchaud S, Billon Y, Meslier F, Robelin D, Calgaro A, LoustauDudez AM, Bonnet N, Yerle M, Acloque H, Ducos A, Pinton A. (2014). Meiotic re- 
combination analyses of individual chromosomes in male domestic pigs (Sus scrofa domestica). PLoS One. 9(6): e99123.

[31] Hornak M, Jeseta M, Musilova P, Pavlok A, Kubelka M, Motlik J, Rubes J, Anger M. (2011). Frequency of aneuploidy related to age in porcine oocytes. PLoS One. 6(4): e18892.

[32] Massip K, Berland H, Bonnet N, Calgaro A, Billoux S, Baquié V, Mary N, BonnetGarnier A, Ducos A, Yerle M, Pinton A. (2008). Study of inter- and intra-individual variation of meiotic segregation patterns in $\mathrm{t}(3 ; 15)(\mathrm{q} 27 ; \mathrm{q} 13)$ boars. Theriogenology. 70: 655-661.

[33] Hook EB. (1977). Exclusion of chromosomal mosaicism: tables of 90\%, 95\% and 99\% confidence limits and comments on use. Am J Hum Genet. 29: 94-97.

[34] Szczerbal I, Nowacka-Woszuk J, Nizanski W, Salamon S, Ochota M, Dzimira S, Atamaniuk W, Switonski M. (2014a). A case of leucocyte chimerism $(78, X X / 78, X Y)$ in a dog with a disorder of sexual development. Reprod Domest Anim. 49: e31-e34.

[35] Dzimira S, Nizanski W, Ochota M, Madej JA. (2015). Histopathological pattern of gonads in cases of sex abnormalities in dogs: an attempt of morphological evaluation involving potential for neoplasia. Pathol Res Pract. 211: 772-775.

[36] Peretti V, Ciotola F, Albarella S, Paciello O, Dario C, Barbieri V, Iannuzzi L. (2008). $\mathrm{XX} / \mathrm{XY}$ chimerism in cattle: clinical and cytogenetic studies. Sex Dev. 2: 24-30.

[37] Esteves A, Bage R, Payan-Carreira R. (2012). Freemartinism in cattle. In: Ruminants Anatomy, Behavior and Diseases (ed. RE Mendes), Nova Science Publishers Inc., New York, USA, 99-120.

[38] Szczerbal I, Kociucka B, Nowacka-Woszuk J, Lach L, Jaskowski JM, Switonski M. (2014b). A high incidence of leukocyte chimerism $(60, \mathrm{XX} / 60, \mathrm{XY})$ in single born heifers culled due to underdevelopment of internal reproductive tracts. Czech J Anim Sci. 59: 445-449.

[39] Nowacka J, Switonski M, Mackowski M, Slota E, Radko A, Zabek T, Urbaniak K. (2004). The use of cytogenetic and molecular techniques reveals ambiguity of the freemartinism diagnosis in cattle. Czech J Anim Sci. 49: 239-243.

[40] Szatkowska I, Switonski M (1996). Evidence on hereditary occurrence of placental anastomoses in heterosexual twins in sheep. Hereditas. 124: 107-110.

[41] Brace MD, Peters O, Menzies P, King WA, Nino-Soto MI. (2008). Sex chromosome chimerism and the freemartin syndrome in Rideau Arcott sheep. Cytogenet Genome Res. 120: 132-139.

[42] Szatkowska I, Zych S Udala A, Dybus A, Blaszczyk P, Sysa P, Dabrowski T. (2004). Freemartinism: three cases in goats. Acta Vet Brno. 73: 375-378. 
[43] Juras R, Raudsepp T, Das PJ, Conant E, Cothran EG (2010). XX/XY blood lymphocyte chimerism in heterosexual dizygotic twins from an American Bashkir curly horse. Case Report. J Equine Vet Sci. 30: 575-580.

[44] Demyda-Peyrás S, Membrillo A, Bugno-Poniewierska M, Pawlina K, Anaya G, Moreno-Millán M. (2013). The use of molecular and cytogenetic methods as a valuable tool in the detection of chromosomal abnormalities in horses: a case of sex chromosome chimerism in a Spanish purebred colt. Cytogenet Genome Res. 141: 277-283.

[45] Barasc H, Ferchaud S, Mary N, Cucchi MA, Lucena AN, Letron IR, Calgaro ABonnet N, Dudez AM, Yerle M, Ducos A, Pinton A. (2014). Cytogenetic analysis of somatic and germinal cells from 38,XX/38, XY phenotypically normal boars. Theriogenology. 81: 368-372.e1.

[46] Beccaglia M, Luvoni GC. (2012). Prediction of parturition in dogs and cats: accuracy at different gestational ages. Reprod Domest Anim. 47 Suppl 6: 194-196.

[47] Demyda-Peyrás S, Anaya G, Bugno-Poniewierska M, Pawlina K, Membrillo A, Valera M, Moreno-Millán M. (2014). The use of a novel combination of diagnostic molecular and cytogenetic approaches in horses with sexual karyotype abnormalities: a rare case with an abnormal cellular chimerism. Theriogenology. 81: 1116-1122.

[48] Bugno M, Słota E, Kościelny M. (2007). Karyotype evaluation among young horse populations in Poland. Schweiz Arch Tierheilkd. 149: 227-232.

[49] Romano JE, Raussdepp T, Mulon PY, Villadóniga GB. (2015). Non-mosaic monosomy 59,X in cattle: a case report. Anim Reprod Sci. 156: 83-90.

[50] Szczerbal I, Nizanski W, Dzimira S, Nowacka-Woszuk J, Ochota M, Switonski M. (2015a). X monosomy in a virilized female cat. Reprod Domest Anim. 50: 344-348.

[51] Pedersen AS, Berg LC, Almstrup K, Thomsen PD. (2014). A tortoiseshell male cat: chromosome analysis and histologic examination of the testis. Cytogenet Genome Res. 142: 107-111.

[52] Pinton A, Barasc H, Raymond Letron I, Bordedebat M, Mary N, Massip K, Bonnet N, Calgaro A, Dudez AM, Feve K, Riquet J, Yerle M, Ducos A. (2011). Meiotic studies of a 38,XY/39,XXY mosaic boar. Cytogenet Genome Res. 133: 202-208.

[53] Reimann-Berg N, Murua Escobar H, Nolte I, Bullerdiek J. (2008). Testicular tumor in an XXY dog. Cancer Genet Cytogenet. 183: 114-116.

[54] De Lorenzi L, Molteni L, Zannotti M, Galli C, Parma P. (2010). X trisomy in a sterile mare. Equine Vet J. 42: 469-470.

[55] O'Connor CL, Schweizer C, Gradil C, Schlafer D, Lopate C, Prociuk U, Meyers-Wallen VN, Casal ML. (2011). Trisomy-X with estrous cycle anomalies in two female dogs. Theriogenology. 76: 374-380. 
[56] De Lorenzi L, Genualdo V, Gimelli S, Rossi E, Perucatti A, Iannuzzi A, Zannotti M, Malagutti L, Molteni L, Iannuzzi L, Parma P. (2012a). Genomic analysis of cattle rob(1;29). Chromosome Res. 20: 815-823.

[57] Iannuzzi A, Di Meo GP, Caputi Jambrenghi A, Vonghia G, Iannuzzi L, Rangel-Figueiredo T. (2008). Frequency and distribution of rob(1;29) in eight Portuguese cattle breeds. Cytogenet Genome Res. 120: 147-149.

[58] De Lorenzi L, Molteni L, Denis C, Eggen A, Parma P. (2008). A new case of centric fusion in cattle: $\operatorname{rob}(21 ; 23)$. Anim Genet. 39: 454-455.

[59] Switonski M., Gustavsson I., Plöen L. (1987). The nature of the 1;29 translocation in cattle as revealed by synaptonemal complex analysis using electron microscope. Cytogeneics and Cell Genetics 44: 103-111.

[60] Bonnet-Garnier A, Pinton A, Berland HM, Khireddine B, Eggen A, Yerle M, Darré R, Ducos A. (2006). Sperm nuclei analysis of 1/29 Robertsonian translocation carrier bulls using fluorescence in situ hybridization. Cytogenet Genome Res. 112: 241-247.

[61] Pinton A, Calgaro A, Bonnet N, Ferchaud S, Billoux S, Dudez AM, Mary N, Massip K, Bonnet-Garnier A, Yerle M, Ducos A. (2009). Influence of sex on the meiotic segregation of a $\mathrm{t}(13 ; 17)$ Robertsonian translocation: a case study in the pig. Hum Reprod. 24: 2034-2043.

[62] Raudsepp T, Chowdhary BP. (2011). Cytogenetics and Chromosome Maps, In: The Genetics of the Pig, 2nd edition (eds. M.F. Rothschild and A. Ruvinsky), CAB International, Wallingford, UK and Cambridge, MA, USA.

[63] Iannuzzi A, Genualdo V, Perucatti A, Pauciullo A, Varricchio G, Incarnato D, Matassino D, Iannuzzi L. (2015). Fatal outcome in a newborn calf associated with partial trisomy 25q and partial monosomy 11q, 60,XX, der(11)t(11;25)(q11;q14 21). Cytogenet Genome Res. 146: 222-229.

[64] De Lorenzi L, Morando P, Planas J, Zannotti M, Molteni L, Parma P. (2012b). Reciprocal translocations in cattle: frequency estimation. J Anim Breed Genet. 129: 409-416.

[65] Lear TL, Lundquist J, Zent WW, Fishback WD Jr, Clark A. (2008). Three autosomal chromosome translocations associated with repeated early embryonic loss (REEL) in the domestic horse (Equus caballus). Cytogenet Genome Res. 120: 117-122.

[66] Szczerbal I, Stachowiak M, Dzimira S, Sliwa K, Switonski M. (2015b). The first case of 38,XX (SRY-positive) disorder of sex development in a cat. Mol Cytogenet. 8: 22.

[67] Kociucka B, Szczerbal I, Bugaj S, Orsztynowicz M, Switonski M. (2014). A high incidence of adjacent-1 meiotic segregation pattern, revealed by multicolor sperm FISH, in a carrier boar of a new reciprocal translocation $t(6 ; 16)(p 13 ; q 23)$. Cytogenet Genome Res. 142: 21-27. 
[68] Massip K, Yerle M, Billon Y, Ferchaud S, Bonnet N, Calgaro A, Mary N, Dudez AM, Sentenac C, Plard C, Ducos A, Pinton A. (2010). Studies of male and female meiosis in inv(4)(p1.4;q2.3) pig carriers. Chromosome Res. 18: 925-938.

[69] Danielak-Czech B, Slota E. (2008). Tandem fusion-translocation: a unique karyotype rearrangement in the domestic pig. Annals of Animal Science 8: 343-348.

[70] Martin-Lluch M, De la Cruz-Vigo P, Ortuno V, Gomez-Fidalgo E, Carrascosa C, Sanchez-Sanchez R. (2014). Cytogenetic study of a reciprocal translocation $(1 ; 6)(q 17 ; \mathrm{p} 11)$ in a subfertile boar. Chromosome Res. 22: 399.

[71] De la Cruz-Vigo, Martin-Lluch M, Gonzalez-Bulnes A, Gomez-Fildago E, Carrascosa C, Sanchez-Sanchez R. (2014). A complex structural translocation with three chromosomes involved in a boar. Chromosome Res. 22: 400.

[72] Barasc H, Mary N, Letron R, Calgaro A, Dudez AM, Bonnet N, Lahbib-Mansais Y, Yerle M, Ducos A, Pinton A. (2012). Y-autosome translocation interferes with meiotic sex inactivation and expression of autosomal genes: a case study in the pig. Sex Dev. 6: 143-150.

[73] García-Vázquez FA, Hernández-Caravaca I, Martín M, Gómez E, Rodríguez A, Sánchez-Sánchez R, Gadea J. (2011). Two cases of reciprocal chromosomal translocation $(4 ; 7)(\mathrm{p}+; \mathrm{q}-)(2 ; 8)(\mathrm{q}-; \mathrm{q}+)$ in piglets produced by ICSI. Reprod Domest Anim. 46: 728730.

[74] Quach A, Revay T, Macedo M, Wyss S, Sullivan B, King WA. (2014). The incidence of translocations in young breeding boars in Canada. Chromosome Res. 22: 397. 
